\title{
A General Theory of Market Competition - M Theory
}

\author{
Chih-Hung Yeh and Tsung-Huai Chang \\ GRF Management et Organisation Université Paris-Dauphine, 75775 Paris, France \\ yfn8@ymail.com, ricci421225@gmail.com
}

\begin{abstract}
We elaborate the firm theory on market structures (with consideration of behavioural doctrine, industry- and firmspecific features) into a General Theory of Market Competition (or $M$ Theory for easy referring) to explore and construct a clearer and more complete theory on essence of the market competition, which encompasses firms' profit-market share relations, the prime subject of PIMS. The General Theory reconciles roughly three-decade disputing arguments and empirical figures on market share-firm's profit relations. $M$ theory upholds positive market share-profit relations, with exception of what we call Market-share Trap where the positive relations is not held or uncertain. We also undertake an empirical study on the global IC foundry industry; the result of positive relations between market share and firm's return is consistent with $M$ theory.

Index Terms - Market Share and Profit, General Theory of Market Competition, M Theory, Market-share Trap, PIMS
\end{abstract}

\section{I . Introduction}

Relations between market share and firms' profit as an unabating current major focus for business executives and scholars attributes to General Electric's internal project directed by Schoeffler on study of the causes of business performance in $1960^{1}$, which had later become the renowned PIMS (Profit Impact of Market Strategy) program in $1970^{2}$, although academic works in this respect went back at least to $1951^{3}$ when relations of firm's profit to market structure and industry concentration were under attention. Much effort had been devoted to establish or nullify positive relations of firm's profit to market share ${ }^{4}$. These endeavours, mostly on empirical studies, seemed to take sights on respective firms or industries, not much eyed on the respective markets ${ }^{5}$ and their situations. Results of these endeavours differed, so did the arguments ${ }^{6}$.

This paper views on the markets and their respective situations, in addition to view on the firms and the industries, to construct a General Theory of Market Competition (or M Theory for easy reference), on the basis of the firm theory regarding to market structures with consideration of behavioural factors, industry- and firm-specific features. $M$

${ }^{1}$ Schoeffler, Buzzell and Heany [19].

${ }^{2}$ PIMS is the most extensive and intensive as well as the most long-lived research project on causes of business profit and performance. It still continues today (see http://pimsonline.com).

${ }^{3}$ Bain [3].

${ }^{4}$ As PIMS and PIMS-related researches had mostly featured on relations of firms' profit to market share, some textbooks and conference participants even referred PIMS as standing for "Profit Impact of Market Share" instead of its original wording.

${ }^{5}$ We roughly distinguish three kinds of market in an economy: the products and services market, the financial assets and contracts market, and the labour market. We call them Physical Market, Financial Market, and Labour Market, respectively. The market under studies in this paper confines to the physical market only.

${ }^{6}$ Buzzell, one of the key scholars in designing and carrying out of PIMS research program in the beginning and early period, had a brilliant annotated review of PIMS and PIMSrelated studies in 2004 [6]. theory upholds positive market share-profit relations, with exception of what we call Market-share Trap (or M Trap) where the relations is not held or uncertain. Referring to different market situations, the General Theory rectifies differed empirical results of our predecessors and their respective arguments. It reconciles roughly three-decade disputing arguments on market share-firm's profit relations; and makes a complete theory of the market competition, rendering satisfactory explanations to different phenomena. As the theory finalised into pivot feature on market share, it could also be referred as a General Theory of Market Share (or Market Share Theory or Market Competition Theory for easy reference).

\section{Outlines of the Paper}

Section 1: the General Theory of Market Competition (M Theory) is explored and constructed with discourse on marketshare trap and causes of market share. Markets are categorised by degree of competition into six types. Characteristics of different markets are probed. Respective optimal firm (market) strategies for different types of market are also enquired.

Section 2: literature review and a concise summary of the predecessors' research results from the perspective of the General Theory, reconciling differed empirical results and arguments.

Section 3: an empirical study on the global IC foundry industry is undertaken. The result of positive market shareROE relations is consistent with the General Theory.

Section 4: concluding notes and implications for business strategy.

\section{II . M Theory}

Starting from elaboration on the profit of firm, we explore and construct a General Theory of Market Competition (M Theory), which generalised the relations of firms' profit to market competition on the full spectrum of market situations.

A. Level of Market Competition and Excess Return ${ }^{7}$

Under long-run static equilibrium, profit maximisation leads to ROE maximisation, as all firms are operating by production (or business) units of the optimal scale with optimal financial leverage. Due to nature of each industry, patent, access to resources, law, technology, know how, corporate strategy, market legacy, brand loyalty, product differentiation, location and other factors, there are different market situations (or types of market) for different industries and each firm might face different market situation in the same

\footnotetext{
Return means return on equity (ROE) in this paper, except otherwise specified or obviously.
} 
industry, under the equilibrium. As a firm's profit is its normal profit (or opportunity cost) plus excess profit (or economic profit), a firm's ROE is its normal ROE plus excess ROE (where: excess $\mathrm{ROE}=$ excess profit / equity).

A firm's normal ROE or its opportunity cost of capital is risk-free return plus risk premium. The risk premium comprises of supply-side risk premium and demand-side risk premium $^{8}$. The higher likelihood (possibility and extent) of operation disruption (production and/or business), the higher supply-side risk premium. The lower certainty of demand the higher demand-side premium. As both are specific for each industry and same for all firms in the same industry under equilibrium with assumption of full knowledge, the risk premium needs no breakdown under equilibrium. Hence,

$$
\begin{aligned}
\mathrm{ROE}= & \text { Risk-free Return }+ \text { Risk Premium } \\
& + \text { Excess Return }
\end{aligned}
$$

The higher risk an industry faces in supply side and in demand, firms in the industry require higher risk premium. Therefore, the risk premium, thus the normal return, is positively related to the industry risk.

The excess return comes from market power under the equilibrium; the stronger a firm commands the market, the higher its excess return would be ${ }^{9}$. In other words, the lower level of market competition the higher excess return. Excess return is inversely related to the level of market competition.

Hence, let $r$ be ROE, $x$ be inverse level of market competition, and $s$ be level of industry risk, a firm's ROE could be expressed as a function of $x$ and $s$ :

$$
r=\mathrm{f}(x, s), \text { where } \frac{\mathrm{df}(x, s)}{\mathrm{d} x}>0 \text { and } \frac{\mathrm{df}(x, s)}{\mathrm{d} s}>0
$$

For firms in the same industry, the second item $=0$, thus:

$$
r=\mathrm{f}(x, s), \text { where } \frac{\mathrm{df}(x, s)}{\mathrm{d} x}>0 \text { and } \frac{\mathrm{df}(x, s)}{\mathrm{d} s}=0
$$

It can be reduced to: $r=\mathrm{f}(x)$, where $\frac{\mathrm{df}(x)}{\mathrm{d} x}>0$

Furthermore, the extent that a firm could lift its excess return is larger when its market power is stronger or the level of market competition is lower. The extreme example is monopoly. On the another extreme, a firm makes zero excess return when it has no or very weak market power, i.e. there is severe or high level of market competition as in the pure competition or monopolistic competition markets, in which a firm might even make negative excess return when it is not in

\footnotetext{
${ }^{8}$ Demand and supply side risks had been explored at least as early as in 1998 by Smeltzer and Siferd [21]. We also assume there is no inflation for simplicity and not diverting from theme of the paper.

${ }^{9}$ In economics, if viewing from the perspective of firms' profit, the firm theory on market structures is all about establishing a theory that a firm's excess profit is positively related to its market power. See e.g., Perloff's Microeconomics of 2012 [15], pp. 248-499.
}

the optimal operation situation ${ }^{10}$, like incurring higher expenses or making price competition - or makes positive excess return when it is in optimal status and its competitors are not, or lifting its under-optimal output, or just out of luck ${ }^{11}$.

Therefore, when there is severe or high level of market competition:

$$
\text { both } \frac{\mathrm{df}(x, s)}{\mathrm{d} x} \text { and } \frac{\mathrm{df}(x)}{\mathrm{d} x}=0 \text { or uncertain }
$$

The situation that a firm could lift its excess return to larger extent at lower level of market competition could be expressed as:

$$
\text { both } \frac{\mathrm{d}^{2} \mathrm{f}(x, s)}{\mathrm{d} x^{2}} \text { and } \frac{\mathrm{d}^{2} \mathrm{f}(x)}{\mathrm{d} x^{2}}>0
$$

\section{B. Market Share and ROE}

We have seen in the previous subsection A that market power or level of market competition determines firms' excess return under equilibrium, yet we did not mention what to gauge the determinant. The most objective, tangible and proper figure would be market share, which is an inverse indicator of market competition. Hence, let $k$ be market share, replacing $x$ by $k$ in all four formulas (2) (3aa) set forth above, the four formulas are still valid. And their meanings become much graspable, clear, and vivid. They are:

$$
\begin{aligned}
& r=\mathrm{f}(k, s) \text {, where } \frac{\mathrm{df}(k, s)}{\mathrm{d} k}>0 \text { and } \frac{\mathrm{df}(k, s)}{\mathrm{d} s}>0 \\
& \text { while } \frac{\mathrm{df}(k, s)}{\mathrm{d} k}>0 \\
& \text { and } r=\mathrm{f}(k) \text {, where } \frac{\mathrm{df}(k)}{\mathrm{d} k}>0
\end{aligned}
$$

Means both market-share elasticity of return ${ }^{12}(\mathrm{~m})$ are positive that if market share increases, so does return (ROE). We would call $m$ as Market-share Effective Coefficient or $M$ Coefficient for easy referring. When there is severe or high level of market competition:

$$
\text { both } \frac{\mathrm{df}(k, s)}{\mathrm{d} k} \text { and } \frac{\mathrm{df}(k)}{\mathrm{d} k}=0 \text { or uncertain }
$$

That means in an intense competition market under the equilibrium, increase in market share would not bring higher return, or even hurt return as the efforts to increase market share would throw the firm out of equilibrium, e.g., operating at non-optimal status with higher marketing expenses in a pure competition market or having to lower price to gain market share in a monopolistic competition market with down sloping demand curve. We call it Market-share Trap (or M Trap) in

\footnotetext{
${ }^{10}$ It means the firm is not in its equilibrium or is in disequilibrium. We shall discuss the subject later in subsection $\mathrm{D}$ next page.

${ }^{11}$ Taking luck or unobservable factors as causes of firms' profit might firstly be argued by Jacobson in 1988 [12].

${ }^{12}$ Buzzell called a similar coefficient the elasticity of profitability with respect to market share or profit-market share elasticity in 2004 [6] p. 479.
} 
the situation of being not able or sure to raise return by lifting market share in an intense competition market ${ }^{13}$.

The situation that firms could have higher returns to larger extent at higher market shares in less competition market could be expressed as:

$$
\text { both } \frac{\mathrm{d}^{2} \mathrm{f}(k, s)}{\mathrm{d} k^{2}} \text { and } \frac{\mathrm{d}^{2} \mathrm{f}(k)}{\mathrm{d} k^{2}}>0
$$

\section{Market-share Characteristic Line (or M Line)}

The relations of ROE to market share could also be clearly depicted by graph like Fig. 1 below. The Y axis is ROE and the $\mathrm{X}$ axis is market share, ranging from near 0 to $100 \%$ to cover the full spectrum of market situations. We call the line portrayed the Market-share Characteristic Line or Market Share Line (or M Line) and the point, which distinguishes the sections on the line of market-share trap ( $\mathrm{M}$ trap) and positive ROE-market share relations, the $M$ Point. The market share at which falls M Point is called the M-Point Market Share or MP Market Share.

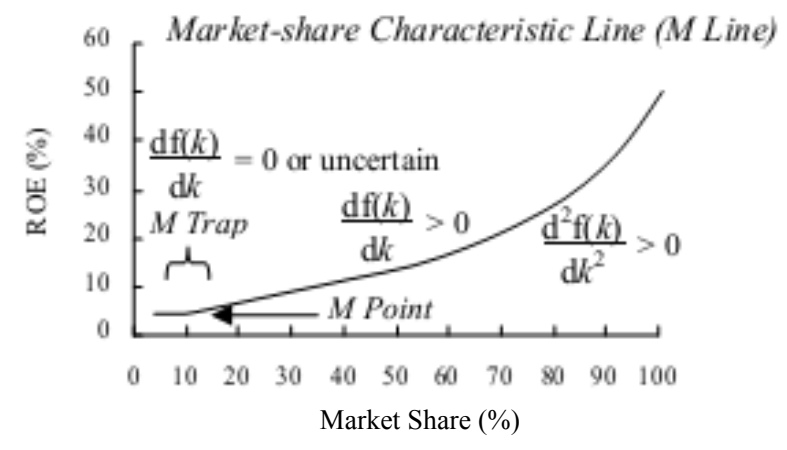

Fig. 1 Positive Relations of ROE to Market Share except at M Trap: Market-share Characteristic Line (M Line).

The $\mathrm{M}$ line section with positive ROE-market share relations could be divided into: a) the section with higher returns to larger extent, which could be called Faster Return Section (the section with $\mathrm{d}^{2} \mathrm{f}(k, s) / \mathrm{d} k^{2}>0$ or $\mathrm{d}^{2} \mathrm{f}(k) / \mathrm{d} k^{2}>0$ as shown on the graph), and b) the section between M Trap and Faster Return Sections, which could be called Moderate Return Section. For the M Trap Section: $\operatorname{df}(k, s) / \mathrm{d} k=0$ or $\mathrm{df}(k) / \mathrm{d} k=0$ that the firm's return equals normal return (= risk-free return + risk premium) as there is no excess return; or $\mathrm{df}(k, s) / \mathrm{d} k$ (or $\mathrm{df}(k) / \mathrm{d} k$ ) is uncertain that the firm may or may not have normal return or may even have negative return. The three sections of M Line - M Trap, Moderate Return and Faster Return Sections correspond to the Intense Competition, Moderate Competition, and Less Competition Markets, respectively. These types of markets will be elaborated later.

Under the equilibrium situation, the $M$ Trap Section is a horizontal line where the firm makes normal return. Under the disequilibrium situation, the M Trap Section might be downsloping when some firms engage in costly marketing endeavours to raise market shares but make lower return; or

\footnotetext{
${ }^{13}$ Simon, Bilstein and Luby urged in 2006 to care more for profit not market share under the situation [20].
}

the M Trap Section might still be up-sloping when some firms are operating at non-optimal status and even suffer losses that the $\mathrm{M}$ Line intersects with the $\mathrm{X}$ axis. Under such situation, the point where the firm makes zero return is called Breakeven Point or BE Point and the market share at the point is called Breakeven Market Share or BE Market Share.

Taking times into consideration instead of just at a point of time, then risk-free return may change and $\mathrm{M}$ Theory could be extended into a more general version:

$$
r=\mathrm{f}(k, s, i)=\mathrm{f}(k, s)+i \text {, where } i \text { be risk-free return }
$$

We call (4) the Firm's Return Function (or just Return Function, or ROE Function or R Function), which is obvious as risk-free return is an additive item of a firm's return, which has been shown in (1). The risk-free return could be correspond to risk-free interest rate and is closely related to business cycle. Since risk-free return is an additive item of a firm's return, the positive ROE-market share relations shall maintain through business cycles ${ }^{14}$.

The M Line derived from Return Function at a point of time or for a period of time for all industries or a group of industries (sector) of the global, regional, national, or area economies, by setting exogenous variables other than $k$ to zero, is a cross-industries M Line, which we called General Market Share Line (or G-M Line) for all industries or Sector Market Share Line (or $S$-M Line) for a group of industries. The $M$ Line derived from $R$ Function for a specific industry of the global, regional, national, or area economies, by setting exogenous variables other than $k$ to zero, could be called Industry Market Share Line (or I-M Line) for the specific industry.

As we have seen that relations of a firm's return to market share is stable over times, the M Line for a specific firm could be derived from R Function (4) using a firm's time series data and setting exogenous variables other than $k$ to zero. It could be called Firm's Market Share Line (or F-M Line).

\section{Equilibrium and Disequilibrium Situations}

We have explored and constructed the General Theory with focus on the static equilibrium, in which all firms are operating at their optimal status, which means they have full knowledge as well as skill and run efficiently at optimal scales with optimal financial leverage, market share comes only from market power or level of market competition. A firm's return is positively related to its market share with exception in the market-share trap, where the firm has no market power.

The market power or level of market competition is attributable to patent, access to resources, law, technology, know how, effective sales networks, corporate strategy, market legacy, brand loyalty, product differentiation, location, etc. Any cost-benefit justified effort to enhance the advantage of these factors or market power will lift ROE, which in fact elevate the firm's optimal status to another well-off optimal status. In the M Trap, almost all these factors do not exist or it

\footnotetext{
${ }^{14}$ Venkatraman and Prescott's 1990 empirical study [23] did show positive market shareprofit relations maintained through business cycles.
} 
is very hard create any advantage in these factors.

If a firm is not at its equilibrium, the firm could raise its ROE, even it is in the M trap, by moving itself toward the equilibrium (or optimal status) through say cost saving, efficiency improving, making optimal leverage, operating at the optimal scale, etc. If in the $\mathrm{M}$ trap, a firm should not undertake price cutting or costly marketing efforts to increase its sales or market share, as that would mostly leads to lower profit and lower ROE.

\section{E. Features of Market-share Characteristic Line (M Line)}

The theory constructed in subsections $\mathrm{A} \sim \mathrm{C}$ is based on the firm theory regarding to market structures with assumption of profit maximisation in a free market economy. The $\mathrm{M}$ line depicted in Fig. 1 is a theoretical General Market-share Characteristic Line for a freely-competed market economy with no or least market control and assumption of profit maximisation. As most modern major and newly-developed economies have regulating laws for fair trade and monopolistic utility enterprises, there are not many firms having very strong market power so that the Faster Return Section would not be very steep. In addition, some firms with natural monopoly or very strong market power attributable to patents, technology, extensive and effective sales networks, innovations, very successful corporate strategies, etc. might adopt a benevolent stance of not pricing their products purely for maximum return and undertaking activities of public interests and charity to have positive public images and good public relations that could also make the faster return section on $\mathrm{M}$ line not being very steep - these types of firms comprising monopoly, oligopoly, and firms with very strong market power could be called collectively as Aliquopoly and their possible benevolent stance could be called Humble Aliquopoly Hypothesis. On the other had, should there is no aliquopoly in a specific industry, the $\mathrm{M}$ line does not have the Faster Return Section.

On the Moderate Return Section, a firm is having some market power through technology, know how, corporate strategy, access to resources, market legacy, brand loyalty, product differentiation, location and other factors. The stronger market power a firm possesses the steeper is the section of M line.

The M Trap Section is flat but very vulnerable to various factors that it might be down-sloping or up-sloping, or might even not exist. These factors include price competition, highcost marketing endeavours, large-scale promotions, inappropriate expansion, over-deployment of capacity, industry-specific or firm-specific feature, increase in underoptimal output, improvement in production inefficiency, change to more effective sales channels, etc.

\section{F. Behavioural, Regulatory, Industry and Firm Factors}

Some firms may have their objectives other than maximum profit, e.g., a forerunner in a rapid-growing market might take a fast pre-empty strategy of maximum sales to prevent emerging of sizable competitors; an internet firm might set its objective at maximum users (or visits, pageviews, etc.) to maximise its firm value; listed firms, in areas with unified par value for shares like in Taiwan, mostly set their objectives at maximum earnings per share (EPS) which tends to have lower ROE than otherwise. Such firms shall have more flat $\mathrm{M}$ line. Firms or industries at debut, growth, or mature stages will have different slope for the section of $\mathrm{M}$ line. These exemplify the behavioural factors that require proper attention.

There are also industry-specific or firm-specific features critical for firm's return. For examples, the most critical factor for the profitability of an IC foundry is probably its yield rate which depends primarily on technology and know how of the foundry; the credit cost ratio is very critical for the profitability of a commercial bank; the regulatory laws and regulations are also critical for the firm's return. These crucial factors should definitely be taken into account. We will incorporate all these factors into our theory in next subsection.

\section{G. The General Theory}

The derivation and discussion in the previous subsection $\mathrm{F}$ included behavioural doctrine and industry- or firm-specific feature. Our General Theory of Market Competition could encompass these firm's behavioural factors as well as industryspecific and firm-specific features into a most generalised version as follows.

$$
r=\mathrm{f}(k, s, i, v)=\mathrm{f}(k, s, v)+i \text {, where }
$$

Let $r$ be ROE, $k$ be market share, $s$ be level of industry risk, $i$ be risk-free return, $v$ be behavioural, regulatory, industryspecific and/or firm-specific factors, then the firm's ROE is a function of $k, s, i$ and $v$ :

$$
\frac{\mathrm{df}(k, s, i, v)}{\mathrm{d} k}>0, \frac{\mathrm{df}(k, s, i, v)}{\mathrm{d} s}>0 \text {, and } \frac{\mathrm{f}(k, s, i, v)}{\mathrm{d} i}>0 ;
$$

except in the Market-share Trap (Space) or M Trap (Space) with low $k$ figures, where

$$
\frac{\mathrm{df}(k, s, i, v)}{\mathrm{d} k}=0 \quad \text { or uncertain; }
$$

at high $k$ figures, there might exists the Faster Return Space, where

$$
\frac{\mathrm{d}^{2} \mathrm{f}(k, s, i, v)}{\mathrm{d} k^{2}}>0
$$

and for Moderate Return Space (which is the space between M Trap and Faster Return Spaces) and M Trap,

$$
\frac{\mathrm{d}^{2} \mathrm{f}(k, s, i, v)}{\mathrm{d} k^{2}} \quad \geq 0
$$

and $\quad \frac{\mathrm{d}^{2} \mathrm{f}(k, s, i, v)}{\mathrm{d} k^{2}}=0 \quad$ or uncertain

Return Function (5) is an obvious extension from (4) by adding the $v$ factor(s). Formulas (5) (7) is the most general version of our General Theory of Market Competition ( $M$ Theory). $\operatorname{df}(k, s, i, v) / \mathrm{d} k$ is the market-share elasticity of return 
(m), which we call the Market-share Effective Coefficient or $M$ Coefficient. The $k$ figure which distinguishes M Trap and Moderate Return Spaces is called M Junction. General, Sector, Industry, and Firm's Market Share (Characteristic) Lines (or $G-M, S-M, I-M$, and $F-M$ Lines) could be derived from Return Function (5) in the similar ways as from Return Function (4).

Here it would be handy to have a brief summarised note: We have derived a General Theory of Market Competition (General Theory of Market Share, or Market Share Theory or Market Competition Theory or M Theory) on the foundation of firm theory regarding to market structures with consideration of behavioural doctrine as well as industry- and firm-specific features. The main assertion of the General Theory is positive relations of firm's return to market share, with exception of Market-share Trap (M Trap) where the positive relations is not held or uncertain. Depending on the competition situation of each industry or each firm, as well as industry- or firmspecific features, S-M, I-M and F-M Market Share Lines might have no Market-share Trap and/or Faster Return Spaces.

\section{H. Generalisation Extension of the Prevailing Firm Theory}

Our General Theory of Market Competition brings the prevailing firm theory on market structures forward to a generalisation on viewing the market as a whole establishment with different degree of competition, which is substantiated by market share, and upon it establishing a system of theory with one of the main assertions being positive relations of firm's return to market share except in the market-share trap. Our theory views monopoly as the situation of no competition on one end and the pure competition as the situation of most severe competition or full competition on the other end, that oligopoly and monopolistic competition are in between, which renders a theoretical framework(s) or model(s) for the full spectrum of the market, making the fundamental principles, causal mechanism, cause-effect logic, interaction structure more clear, easier for grasp and more simple to handle, upon which one can studies or analyses with relative clarity and easiness - its application to the un-waning subject of market share-profit relations is an obvious example.

In comparison, the prevailing firm theory is based on the respective theories ranging from pure competition to monopoly, lacking a framework to encompass these kinds of market scenarios into a market with full range of different situations. It makes the common principles, mechanism, causal logic, interaction structure losing its common platform in dividing the market into seemingly-not-related different markets of pure competition, monopoly, etc., making it not being viewed as a market, losing clarity in fundamental principles and mechanism, and making it difficult for handle in study and analyses of the market as a whole or a single establishment.

Table 1 Six Types of Market

\begin{tabular}{|c|c|c|c|c|c|c|c|c|}
\hline \multirow[b]{2}{*}{ Category } & \multirow[b]{2}{*}{ Six Types of Market } & \multirow[b]{2}{*}{ Market Share } & \multirow[b]{2}{*}{$\begin{array}{l}\text { Excess } \\
\text { Return }\end{array}$} & \multirow[b]{2}{*}{$\begin{array}{l}\text { M Line } \\
\text { Sections }\end{array}$} & \multicolumn{2}{|c|}{ M Coefficient } & \multirow[b]{2}{*}{$\begin{array}{l}\text { Market } \\
\text { Structure }\end{array}$} & \multirow[b]{2}{*}{ Optimal Firm Strategy } \\
\hline & & & & & $\frac{\mathrm{df}(k, s \ldots)}{\mathrm{d} k}$ & $\frac{\mathrm{d}^{2} \mathrm{f}(k, s \ldots)}{\mathrm{d} k^{2}}$ & & \\
\hline \multirow{2}{*}{$\begin{array}{c}\text { Less } \\
\text { Competition }\end{array}$} & No Competition & Total & Very High & \multirow{2}{*}{$\begin{array}{l}\text { Faster } \\
\text { Return }\end{array}$} & \multirow{2}{*}{$>0$} & \multirow{2}{*}{$>0$} & Monopoly $^{\mathrm{b}}$ & \multirow{2}{*}{$\begin{array}{c}\text { Humble Aliquopoly Strategy: good public relations for } \\
\text { highest possible ROE \& longest market power }\end{array}$} \\
\hline & Few Competition & High & High & & & & Oligopoly, etc $^{\text {a }}$ & \\
\hline \multirow{2}{*}{$\begin{array}{c}\text { Moderate } \\
\text { Competition }\end{array}$} & Low Competition & Fairly High & Moderate & \multirow{2}{*}{$\begin{array}{l}\text { Moderate } \\
\text { Return }\end{array}$} & \multirow{2}{*}{$>0$} & \multirow{2}{*}{$\geq 0$} & Firms/ Strong Po ${ }^{c}$ & \multirow{2}{*}{$\begin{array}{c}\text { Difference Enhance Strategy: increase popularity, loyalty \& } \\
\text { long-run market power by more difference }\end{array}$} \\
\hline & Modest Competition & Fair & Some & & & & Firms/ Some Po ${ }^{d}$ & \\
\hline \multirow{2}{*}{$\begin{array}{c}\text { Intense } \\
\text { Competition }\end{array}$} & High Competition & Low & \multirow{2}{*}{$\begin{array}{l}\text { None or } \\
\text { Negative }\end{array}$} & \multirow{2}{*}{ M Trap } & \multirow{2}{*}{$\begin{array}{c}=0 \text { or } \\
\text { uncertain }\end{array}$} & \multirow{2}{*}{$\begin{array}{c}=0 \text { or } \\
\text { uncertain }\end{array}$} & Monopolistic $\mathrm{Co}^{\mathrm{e}}$ & \multirow{2}{*}{$\begin{array}{l}\text { Optimal Status Strategy: keen on optimal status \& shifting } \\
\text { to cozy market; careful on costly marketing }\end{array}$} \\
\hline & Severe Competition & Very Low & & & & & Pure Competition & \\
\hline
\end{tabular}

${ }^{a}$ etc means firms with very strong market power. ${ }^{a}$ and $b$ together includes monopoly, oligopoly, and firms with very strong market power - we call collectively these three types of firm Aliquopoly. ${ }^{\mathrm{c}}$ Firms with strong market power. ${ }^{\mathrm{d}}$ Firms with some market power. ${ }^{\mathrm{e}}$ Monopolistic competition.

\section{Six Types of Market}

The markets faced by firms could be categorised by level of competition: less (no and few), moderate (low and modest), and intense (high and severe) competition, as shown in Table 1 above. The less competition market structure comprises of monopoly, oligopoly and firms with very strong market power - we call them collectively Aliquopoly. Degrees of market power possessed by the firms in the six types of market are almost total, very strong, strong, some, almost none and no, respectively. Relative characters are also exhibited. The respective firms' utmost strategies for different markets are possibly:

1) Humble Aliquopoly Strategy for Less Competition Markets: With total or very strong market power, Aliquopolists have total or high market shares enjoying very high or high ROE. For these firms, it is paramount important to have such market structures sustained as long years as possible. Since these market structures are much vulnerable to criticism and public antipathy, it is imperative to undertake activities of public interests and charity for winning of positive public images and relations while maintaining highest possible ROE. Total and high market shares are features of these market structures and the key for very high and high ROE. Of course, aliquopoly firms have to devote consistently efforts to maintain advantages in the causes of their market status, like technologies, know how, extensive and effective sales networks, etc. In a word, market share matters.

2) Difference Enhancing Strategy for Moderate Competition Markets: Key factors for the fairly-high and high market shares with relatively high ROE enjoyed by firms in 
these markets is differentiation in their products, brands, firm images, technologies, know how, business networks, etc. Hence, the most important thing for these firms is persistently enhancing their differences and uniqueness to constantly increase or sustain popularity and loyalty of their products (or services) as well as their long-run market power. Again, market share matters.

3) Optimal Status Strategy for Intense Competition Markets: In these high or severe competition markets, it is very hard to increase ROE, but easy to hurt ROE, through increase in market share as it often takes tolls on lower prices, costly marketing endeavours and/or low-margin promotions. Consequently, it is critical to have a firm operates at optimal status enjoying top efficiency and lowest cost that upholds normal or even higher ROE. It is even more important to devote best efforts for shifting into lower competition markets through perhaps new businesses. Here, a firm has to care most about its optimal status in the existing business - market share does not matter. However, more importantly the firm needs to try best for shifting into lower competition market - market share does matter, after all.

\section{Literature Review and Notes on Predecessors' Studies}

Theory of relations between firm's profit and market competition could be traced back at least to the origination of the modern economics in 1776. Empirical study in this respect seems starting at least in 1951 when relations of firm's profit to market structure and industry concentration were under attention. However, governmental regulation on inappropriately high industry concentration began at least by Sherman Act 1890 in the United States, seemingly much earlier than academic empirical studies on the firm's profitmarket competition relations.

\section{A. Theory of Positive Market Share-Profit Relations}

Theory of negative profit-competition relations, or we will use positive profit-less competition relations in the following text of the paper, goes back at least as far as the origin of modern economics in Adam Smith's 1776 epoch-making Wealth of Nations as he talked about the invisible hand that competition is equaling rates of return for firms and eroding excess gains [22]. It is the core spirits of his laissez-faire and free trade doctrine. His view of competition was the prototype of the present pure competition ${ }^{15}$. He mentioned many sellers, full information and full resources mobility as prerequisites for competition $^{16}$. He also talked about number of sellers affect their ability to influence price. These in fact stated the very core essence of the positive profit-less competition relations. Smith also talked about the monopoly power on selling price and hinted situation of what we called moderate competition by noting that "secrets of manufacture" induces monopoly.

The prevailing firm theory regarding to market structures came roughly to its present contents with more kinds of market situations in the 1930s when Chamberlin and Robinson

\footnotetext{
${ }^{15}$ We use pure competition instead of perfect competition as termed by the present Economics. Perfect competition is easily misleading in our view.

${ }^{16}$ Smith just did not refer the homogeneous condition for pure competition.
}

published Theory of Monopolistic Competition and Economics of Imperfect Competition in 1933, respectively [7][17]. It since seems not having significant or meaningful additions up to the present and lacking a theoretical framework tool to handle the market as a whole instead of treating separate market situations of pure competition, monopolistic competition, oligopoly, monopoly, etc., like studying relations of market competition to firm's profit or, more specifically, relations of firm's profit to market share. We believe our General Theory of Market Competition (M Theory) as a generalisation extension fills the gap. $M$ Theory also renders a straight foreword and explicit theoretical framework for model specification and theoretical interpretation foundation in empirical study of the relations between firm's profitability and market competition.

The relations of Firm's profit to market share in economic theory from the very beginning to the present is definitely positive, even taking behavioural, industry- and firm-specific factors into consideration. It is just a common sense. If ask an ordinary person, would a firm having 90 or 70 or $60 \%$ market share in ordinary years without any price-control regulation makes lower return than a firm in the same industry with 30 or 20 or $10 \%$ market share does? Who will give an affirmative answer? The theory just gives formal rigorous derivations. However, there do exist the situations when the market is under intense competition where firms with low market shares try costly marketing and/or promoting endeavours would very likely end with lower return even had market shares lifted. No any theory touched upon the subject before, although there are arguments in this respect by at least Simon, Bilstein and Luby in 2006 [19]. Market-share Trap brought forth by M Theory fills the vacancy.

\section{B. Empirical Studies up to the Present}

The earliest academic empirical study on relations of firm's profitability to competition was at least done in 1951 by Bain [3], although he used industry concentration as the gauge for competition, which was the focus subject in 1930s through 1950s. However, we believe statistical data compilation and statistical studies on firms' profit, monopoly, cartels, collusions, and/or industry concentration in governmental and legislative entities could go back at least to 1880 s as Sherman Act, an United States antitrust law, was passed in 1890.

The most notable and large-scale studies on the relations of firm's profit to market share was initiated by General Electric's internal project on study of the causes of business performance in $1960^{17}$, which had later become the renowned PIMS (Profit Impact of Market Strategy) program in 1970. Despite that the General Electric project and PIMS were not specifically focused on market share, the most notable findings were positive relations of firm's profitability to market share. They attracted extensive and enormous attention; and started an un-abating and substantial study wave on the subject up to the present. It had dominated marketing strategy research

\footnotetext{
${ }^{17}$ Schoeffler, Buzzell and Heany [19] p. 138.
} 
between 1975 and $1990^{18}$ and is still one of the most popular study subjects in marketing. The vast majority of study results were consistent to the positive relations and all the remarks were supportive until probably the earliest in 1985 when Jacobson and Aaker attributed the positive relations to joint outcome of some third factor(s) [10]. Their study did not denied the positive relations but they did not view market share as the real source of a firm's profit. We take the same view but from a different perspective that market share came from advantages in fundamental elements, like patent, access to resources, law, technology, know how, effective sales networks, corporate strategy, market legacy, brand loyalty, product differentiation, location, etc. Through elevating in the fundamental virtues to gain market share and through market share to enhance market power; and through market power a firm could increase it excess return.

The criticism to the statement or theory of positive market share-profit relations are primarily in two aspects.

Firstly, the view of market share is not the source of profit that the empirical positive market share-profit relationship is just results of third factor(s) or unobservable factor(s). These include Rumelt and Wensley [18], Jacobson and Aaker in 1987 [11], Jacobson in 1980 and 1988 [9][12]. These predecessors tried by statistical methods to identify those third factors, usually with limited success or came to general factors without much strategic implications. Simon, Bilstein and Luby did propose extensive measures to raise profit in the intense competition market in 2006 [20].

Secondly, the view of existence of firms with low market shares making good profit and empirical evidences of the view by Woo and Cooper in 1981 and 1982 [25][26]. The other way is to present that there are firms with high market shares but making relatively less profit by Woo [24]. These views did not make in the context of the whole industry landscape or the overall industrial landscape in an economy to see the complete picture and situation of the industry.

All the empirical studies from 1960s up to the present we were aware seemed being made without fundamental theory structures, frameworks, or backing. These studies were just utilising statistical or econometrical methods to find from many possible factors those having more impacts on profitability. These empirical studies if made in the context of market situation with backing of or under a structure or framework of some theory taking due consideration about the specific features of respective industries and incorporating the special features into the empirical structures or models, the results would be of much significant in the strategic as well as operational perspectives.

\section{Empirical Study on the Global IC Foundry Industry}

Following General Theory of Market Competition (M Theory), we undertake an empirical study on the global IC (integrated circuit) foundry industry to see whether the firms' return follow the theory; and particularly whether it is in

\footnotetext{
${ }^{18}$ Buzzell [6] p. 478.
}

conformity with the positive market share-firm's return relations. Furthermore, the empirical study under M Theory also establishes pragmatic firms' return functions that help to understand the industry and the firms much intensively and to render much strategic and operational implications and insights. In fact, we carry out empirical studies on the global IC foundry industry and seven IC foundries.

IC foundry industry is probably one of the most unique industries on the globe. Despite of being a most technical and capital intensive manufacturing industry producing most difficult and sophyscated semiconductive electronic devices involving controlled-sensitive technology, the product it sells is absolutely homogeneous with trivial transportation cost - it sells just services, service of IC fabrication. It is naturally an industry of keen competition globally. There is a minor exception in the very special GaAs process foundry for GaAs MMIC's (monolithic microwave ICs) and RFIC's (radio frequency ICs), which constitutes a very special IC foundry segment or market due to very special fab equipment and very small application market compared to the overall foundry market. Win, one of the foundries under our empirical study, is specialised in and dominant the GaAs IC foundry segment with $62.4 \%$ market share in $2012^{19}$, despite its tiny scale in the industry.

Aside from the minor exception of GaAs process mentioned above, all the IC foundries virtually face just one global market. One factor that the foundry could compete to one another is technology - technology and know how of production, production process and production management, which results in how sophyscated the fabrication and what is the yield a foundry could bring forth. Equipment and capacity would not be an issue, should one foundry have advantage in technology.

The other major factor comes from the very capitalintensive nature of IC fabrication. One 12-inch IC fab costs about US $\$ 3.5$ billions nowadays. The depreciation charge is definitely horrible if the utilisation rate is low. Considering the existing capacity and further growth of one IC foundry, utilisation rate is closely related the foundry's market share. On the other hand, as foundry changes fabrication each time for each order of different product, the yield rate varies with different products as well as other possible disturbances, like earth quake, drain, sudden power blackout. The yield rate thus affects both operating margin (OPM) and market share. Of course, the fundamental determinant for a more consistent and higher yield rate is the foundry's level of technology. With these features of IC foundry understood, we have two key factors for a foundry's return (ROE) from operational as well as strategic perspectives: market share and yield rate.

\section{A. The Empirical Model}

Following our M Theory, for an IC foundry as a firm, we have market share and the industry-specific factor of yield rate as determinants for the firm's return. Since yield rate data could not be comprehensively acquired and it is directly

\footnotetext{
${ }^{19}$ WIN Semiconductors Company Presentation, 6 May 2013.
} 
reflected in operating margin (OPM), we will use OPM in the place of yield rate. Furthermore, in view of that yield rate might affect both market share and OPM, market share and OPM might be related. We therefore convert OPM into a proxy variable $v$ which is not related to market share but still reflect the level of yield rate - we will revert to it later.

As the industry risk and risk-free return for all IC foundries are virtually the same, or we assume them be same over the period that they could be reduced to a constant. Assume there is no significant difference in firms' behavioural and firm-specific factors, then following the general version of M Theory and considering the very feature of IC foundry industry, return function (5) could be specifically formulated into the following equation for our empirical study.

Let $r=\mathrm{ROE} ; k=$ market share; $v=$ proxy for OPM; a, b, and $\mathrm{g}$ be constants; and $e$ be disturbance, then the Return Function (R Function) could be expresses as

$$
r=\mathrm{a}+\mathrm{b} k+\mathrm{c} / k+\mathrm{g} v+e
$$

Due to different situations of the IC foundry Industry and each foundry, c and/or $g$ and/or even b might not exist sometimes.

\section{B. Data}

Generally, we use thirty-eight quarterly after-tax return on equity (ROE), OPM and sales (some foundries have shorter histories) as well as market shares of seven listed foundries among the 2012 global top ten ${ }^{20}$ from third quarter 2003 through 2012 (3Q03 2012).

Table 22012 Global Top Ten IC Foundries \& Market Shares

\begin{tabular}{|c|c|c|c|c|c|}
\hline \# & Firm & Domicile & $\mathrm{MS}^{\mathrm{a}}$ & Sales $^{\mathrm{b}}$ & Foundry Name \\
\hline 1 & TSMO & Taiwan & 44.4 & 16.9 & Taiwan Semiconductor Manufacturing Co \\
\hline 2 & GF & UAE & 12.0 & 4.6 & GlobalFoundries Inc \\
\hline 3 & SS & S. Korea & 11.4 & 4.3 & Samsung Semiconductor \\
\hline 4 & $\mathrm{UMC}$ & Taiwan & 9.4 & 3.6 & United Microelectronics Corp \\
\hline 5 & SMIC & M.China ${ }^{\mathrm{c}}$ & 4.5 & 1.7 & Semiconductor Manufacturing Int'l Corp \\
\hline 6 & $\mathrm{HHG}$ & M.China $^{\mathrm{c}}$ & 2.5 & 0.9 & Hua Hong Grace Semiconductor \\
\hline 7 & TSL & Israel & 1.7 & 0.6 & Tower Semiconductor Ltd \\
\hline 8 & VIS & Taiwan & 1.5 & 0.6 & Vanguard Int'l Semiconductor Corp \\
\hline 9 & $\mathrm{DB}$ & S. Korea & 1.4 & 0.5 & Dongbu HiTek Co Ltd \\
\hline \multirow[t]{2}{*}{10} & Win & Taiwan & 1.0 & 0.4 & Win Semiconductors Corp \\
\hline & Others & & \begin{tabular}{|l|l}
10.3 \\
\end{tabular} & 3.9 & \\
\hline
\end{tabular}

${ }^{\mathrm{a}}$ Market share (\%). ${ }^{\mathrm{b}}$ US\$ billions. ${ }^{\mathrm{c}}$ Mainland China. Source: IC Insight web, Bloomberg, companies.

For the period, financial statements data are available and accessible through financial information providers' data banks, in this case Bloomberg. Brief information about 2012 ranking, market share and sales for the global top ten foundries are shown in Table 2 above. The market share is the sales of each foundry divided by the aggregate sales of the industry. The aggregate sales of the industry came from IC Insight web, adjusted by the sales reported by the seven listed foundries. Some figures were missing in the data bank we accessed and

\footnotetext{
${ }^{20}$ IC Insights web (http://icinsights.com)
}

some extreme figures were deleted. The results are 201 sets of market share, ROE and OPM figures.

On regression of the industry data, designated by (17) in Table 4, data of Win are not used due to its very small market share of $0.8 \sim 1.1 \%$ but with the second highest ROE level, averaged $14 \%$ for the two years of 2011 through 2012, which would make regression unable being carried out if added to the data of the other six foundries. Hence, there are 193 sets of figures used in the regression for the industry. Count of the figure sets used in the regression for each foundry are listed on Table 3, which gives a general data statistics for an overview of the data used.

As mentioned in subsection $\mathrm{A}$, operating margin (OPM) is often related with market share that we have to convert it into proxy variables, which are not related to market share. In this study, we use three proxy variables $\left(v_{1}, v_{2}\right.$ and $\left.v_{3}\right)$ in the place of yield rate. $v_{1}$ is OPM without conversion, which is used where market share does not affect firm's return and is not used in regression as an exogenous variable that there is no collinearity problem like (20) in Table 4 below.

Table 3 Market Share, ROE, Yield Proxy and OPM: Data Statistics

\begin{tabular}{|c|c|c|c|c|c|c|c|c|c|}
\hline \multicolumn{3}{|c|}{ Regressions : } & \multicolumn{4}{|c|}{$E(r)=\mathrm{a}+\mathrm{b} k+\mathrm{c} / k+\mathrm{g} v$} & \multicolumn{3}{|c|}{ 3Q03 2012 } \\
\hline & Firm & All & TSMC & UMC & SMIC & TSL & VIS & DB & Win \\
\hline \multirow{4}{*}{ 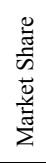 } & Count & 193 & 38 & 38 & 34 & 8 & 38 & 37 & 8 \\
\hline & Mean & 0.15 & 0.47 & 0.15 & 0.06 & 0.018 & 0.021 & 0.047 & 0.010 \\
\hline & High & 0.55 & 0.55 & 0.22 & 0.09 & 0.023 & 0.031 & 0.098 & 0.011 \\
\hline & Low & 0.01 & 0.40 & 0.09 & 0.04 & 0.015 & 0.013 & 0.012 & 0.008 \\
\hline \multirow{3}{*}{ 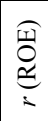 } & Mean & 0.06 & 0.23 & 0.05 & -0.04 & -0.15 & 0.12 & -0.05 & 0.14 \\
\hline & High & 0.34 & 0.34 & 0.21 & 0.22 & 0.09 & 0.31 & 0.29 & 0.25 \\
\hline & Low & -0.47 & 0.01 & -0.46 & -0.27 & -0.47 & -0.15 & -0.45 & 0.05 \\
\hline \multirow{3}{*}{ 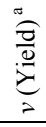 } & Mean & 0.02 & 0.01 & -0.00 & -0.00 & - & 0.00 & -0.02 & - \\
\hline & High & 0.37 & 0.08 & 0.17 & 0.31 & - & 0.19 & 0.12 & - \\
\hline & Low & -0.72 & -0.20 & -0.71 & -0.48 & - & -0.61 & -0.42 & - \\
\hline \multirow{3}{*}{$\sum_{\substack{0 \\
0}}$} & Mean & 0.09 & 0.34 & 0.07 & -0.09 & 0.04 & 0.14 & -0.01 & 0.20 \\
\hline & High & 0.43 & 0.43 & 0.26 & 0.17 & 0.16 & 0.34 & 0.12 & 0.26 \\
\hline & Low & -0.68 & 0.08 & \begin{tabular}{|l|}
-0.68 \\
\end{tabular} & -0.57 & -0.06 & -0.50 & -0.26 & 0.09 \\
\hline
\end{tabular}

Let $k$ be market share, for an earlier 218 sets of OPM $\left(v_{1}\right)$ and market share $(k)$, we carried out a regression and got

$$
\mathrm{E}\left(v_{1}\right)=-0.05+0.82 \mathrm{k}+e_{1}
$$

Where both constants and $\mathrm{F}$ were significant at 0.01 level and $\mathrm{R}^{2}=0.338$. It is a valid regression that $v_{1}$ is about $33.8 \%$ related to $k$. We then let $v_{2}=e_{1}$ be the second yield-rate proxy variable. We used $v_{2}$ in (17), (18) and (23) for regressions.

For (19) and (22), we used the same simple linear regression on UMC and DB. For (19), the regressed two constants and $\mathrm{F}$ are all not significant at 0.05 level; $\mathrm{R}^{2}=0.043$. For (22), interception constant is not significant at 0.05 level; variable constant is significant at 0.01 level; $F$ is significant at 0.05 level, while $\mathrm{R}^{2}=0.154$. Despite that the two regressions are not valid, the residual variables could still serve the purpose as proxies for yield rate. The regression results are shown in Table 4 above. They are all valid regressions, except 
(24). For $(17) \sim(23)$, most constants are significant at 0.01 level; two constants are significant at $0.05 \mathrm{level}$; four interception constants are not significant at 0.05 level which do not affect the validity of the regressions for the main purpose of these regressions are to see if there are associations between the firms' return and market share and/or the yield proxies.

Table 4 Regressions for Firm's Return Function (R Function): Foundry Industry

\begin{tabular}{|c|c|c|c|c|c|c|c|c|c|}
\hline & \multicolumn{3}{|c|}{3 Q03 2012 } & \multicolumn{6}{l|}{ Regressions: $E(r)=\mathrm{a}+\mathrm{b} k+\mathrm{c} / k+\mathrm{g} v$} \\
\hline$\#^{\mathrm{a}}$ & Firm & MS $^{\mathrm{b}}$ & Count & $\mathrm{a}$ & $\mathrm{b}$ & $\mathrm{c}$ & $\mathrm{g}$ & $\mathrm{adj} \mathrm{R}^{2}$ & $\mathrm{~F}$ \\
\hline$(17)$ & All & 0.15 & 193 & 0.003 & $0.487^{* *}$ & $0.001^{* *}$ & $0.611^{* *}$ & 0.61 & $99^{* *}$ \\
\hline$(18)$ & TSMC & 0.47 & 38 & -0.06 & $0.06^{* *}$ & - & $0.93^{* *}$ & 0.83 & $94^{* *}$ \\
\hline$(19)$ & UMC & 0.15 & 38 & -0.06 & $0.71^{*}$ & - & $0.46^{* *}$ & 0.46 & $17^{* *}$ \\
\hline$(20)$ & SMIC & 0.06 & 34 & -0.002 & - & - & $0.445^{* *}$ & 0.51 & $35^{* *}$ \\
\hline$(21)$ & TSL & 0.018 & 8 & $-0.64^{* *}$ & $24.09^{* *}$ & - & - & 0.32 & $9^{*}$ \\
\hline$(22)$ & VIS & 0.021 & 38 & $-0.09^{* *}$ & $9.96^{* *}$ & - & $0.47^{* *}$ & 0.78 & $68^{* *}$ \\
\hline$(23)$ & DB & 0.05 & 37 & $-0.21^{* *}$ & $3.55^{* *}$ & - & $0.56^{* *}$ & 0.30 & $9^{* *}$ \\
\hline$(24)$ & Win & 0.010 & 8 & $-5.98^{\mathrm{d}}$ & $336.53^{\mathrm{c}}$ & $0.03^{\mathrm{e}}$ & - & 0.21 & 2 \\
\hline
\end{tabular}

${ }^{\mathrm{a}}$ Formula number. ${ }^{\mathrm{b}}$ Average market share. ** Significant at $0.01 \%$.* Significant at $0.05 \%$. ${ }^{\mathrm{cde}}$ Significant at $7.25,8.20$ and $8.45 \%$, respectively.

\section{The Results are Consistent to M Theory}

The regression results show a variety of relations between firms' return, market share, and yield proxies or operating margin, which are in conformity with $\mathrm{M}$ Theory. The empirical results for the global foundry industry can be vividly shown by two charts (see Fig. 2 and 3).

Main findings of the empirical study are:

1) Positive market share-return relations is upheld with exception of Market-share Trap, in which SMIC is stuck and could not find relations between its return and market share.

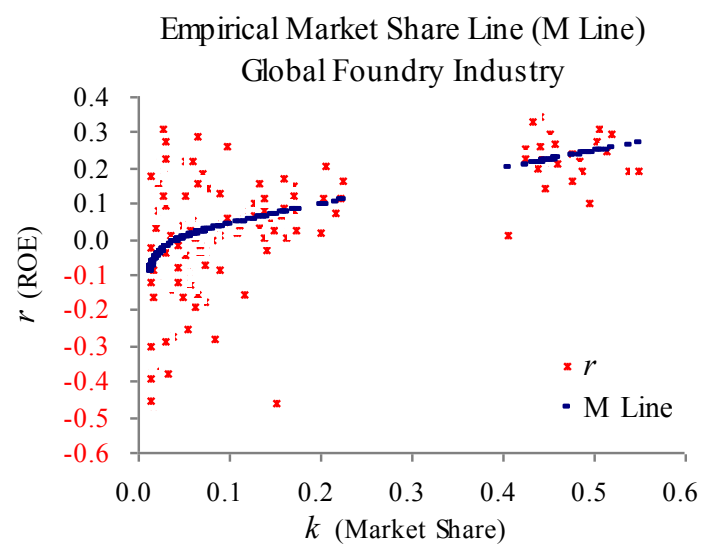

Fig. 2 Empirical Market-share Characteristic Line (M Line) for the Global Foundry Industry.

2) For the Industry Market Share Line (see Fig. 2 above), Market-share Trap exists and M Point falls roughly at $12 \%$ market share, assuming normal return be 5\%. The Breakeven Market Share is about 5\%; foundries with market share below $5 \%$ are struggling to get rid of losses due to backwards in technology and know how. VIS and Win are two exceptions with market share below $2.5 \%$, which made steady positive returns. The reasons are: a) VIS is a subsidiary of the top foundry TSMC that it is virtually a division of TSMC; b) Win is a foundry of special GaAs process and in that special market segment it actually had very high market shares of $54 \%$ and $62 \%$ in 2011 and 2112 , respectively ${ }^{21}$.

3) In the Market-share Trap, positive market share-firm's return relationship is mostly still held. As the yield rate affect both return and market share, when yield rate rises, both return and market share climb.

4) The Industry Market Share Line (I-M Line) has a steep section in Market-share Trap and no Faster Return Section. The foundries in the market-share trap are suffering with low yield rates. Improvement in the yield rate would fast lift return while it could only push the market share slightly. Despite being the industry overwhelming leader with the lion market share of 40 to $55 \%$ and averaged at $47 \%$, TSMC still faces competition from its peers and could not have its price too much higher then other foundries that the I-M Line does not have Faster Return Section. The far-ahead spot cluster above $40 \%$ market share in Fig. 2 belongs solely to TSMC.

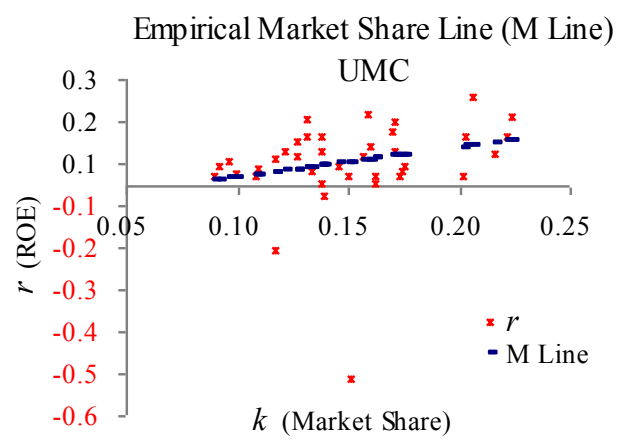

Fig. 3 Empirical Market-share Characteristic Line (M Line) for UMC.

5) The Market Share Lines for most of the foundries (five among seven) are linear, like UMC (see Fig. 3 above), while TSMC be the far-ahead leader commanding around half of the market. The five foundries with linear M Lines are TSMC, UMC, TSL, VIS, and DB; see (18), (19), (21) (23) in Table 4 in the previous page.

6) Relations between market share and foundry's return might not exist for some foundries. SMIC does not have the relation while Win is unsure about the relation, which means the Market Share Line does not exist or is unsure. SMIC is stuck in Market-share Trap and slightly under the breakeven point persistently. Its yield rate fluctuates substantially that destroys the relations between market share and return. Win enjoys steadily fair return averaging $14 \%$ in its special market segment with very small market share of around $1 \%$ in the overall foundry market. The only major variation to return came from yield rate that the market share-return relations is not definite in our regression.

\footnotetext{
${ }^{21}$ WIN Semiconductors Company Presentation, 6 May 2013.
} 


\section{Concluding Notes and Strategic Implications}

There seems lacking an integrated theoretical framework for analysis and study of the mechanism of firm's market power to its return under different market competition situations from the perspectives of each firm as well as the industry or the overall economy as a whole. In this paper we explored and established a General Theory of Market Competition that fills the vacancy. The theory also renders theoretical backing or a theoretical framework or structure for undertaking empirical studies in more meaningful and productive ways.

\section{A . Summary of M Theory and Empirical Study on IC Foundry}

In this paper, a General Theory of Market Competition (or General Theory of Market Share or Market Share Theory or Market Competition Theory or just M Theory) is explored and established, basing on the firm theory regarding to the market structures, with considerations to the behavioural doctrine as well as industry- and firm-specific features. Main assertion of the General Theory is positive market share-firm's return (ROE) relations, with exception of Market-share Trap (or M Trap) where the relations is not held or be uncertain.

Core essence of M Theory is formulation of the Firm's Return Function (or Return Function, or R Function), from which Market-share Characteristic Line (or Market Share Line or M Line) could be derived. Besides Market-share Trap, there are Faster Return Section at very high market shares and Moderate Return Section at modest market shares on the Market Share Line. The point, which distinguishes M Trap and the Moderate Return Section, is called M Point. The market share at M Point is called the M-Point Market Share or MP Market Share. The point with zero return on M Line is called Breakeven Point or BE Point and the market share at the point is called Breakeven Market Share or BE Market Share.

Depending on the data used, empirical General, Sector, Industry and Firm's Market Share Lines (or G-M, S-M, I-M and F-M Lines) can be constructed. From empirical M Line, Market-share Effective Coefficient (or M Coefficient) could be calculated, which shows the extent market share will affect firm's return (ROE). According to the level of competition, the markets could be categorised into six types of market with different characters and appropriate strategies as exhibited in Table 1. Due to different competition situation of each industry or each firm, as well as industry- or firm-specific features, S-M, I-M and F-M Lines might have no Market-share Trap and/or Faster Return Spaces.

We have undertaken an empirical study on the global IC foundry industry, basing the $\mathrm{M}$ Theory Model. Through regressions, eight $\mathrm{R}$ Functions were constructed for the industry and seven foundries, two of which are nonlinear. The results are consistent with $M$ Theory that positive market share-firm's return relations is upheld with (for some foundries) positive slope in the Market-share Trap as most foundries in the M Trap are backwards in technology with under-optimal output and struggling to get out of losses. For one foundry, SMIC, there is no relationship between market share and ROE as it is constantly suffering losses and some improvements in yield rate lifts profit greatly but only pushes market share slightly and because its yield fluctuates at the low output level that market share is something unreachable to it. There is no Faster Return Section on IC foundry industry's M Line as all foundry virtually sell a very homogeneous product, IC fabrication service, the overwhelming market leader with a market share of around 50\% could not charge too high of the price as it still faces knee competition from it peers.

\section{$B$. Strategic Implications from $M$ Theory}

Market share based on the fundamental advantages usually brings market power to generate excess return; the stronger market power brings higher excess return. A firm's utmost endeavour is probably to persistently enhance its fundamental advantage, which is attributable to innovation, patent, access to resources, law, technology, know how, corporate strategy, market legacy, brand loyalty, product differentiation, location and other factors. Saying that, it means a firm basically needs to stay always in the optimal status that it operates at optimal level of output, cost, expense, scale of factory and/or business networks with optimal leverage; then it has the competing competence. The firm could always increase it return by moving closer to the optimal status; it could also raise its return by pushing itself to a higher or better optimal level.

In an intense competitiom market, a firm has to be very cautious to undertake costly extra marketing endeavour and /or extra huge promotions as it would often end in hurting return despite possible gains in market share. For firms suffering persistent losses have to take bold strategic move to get out of fundamental backwardness at even seemingly extraordinary huge cost; otherwise there is probably no way out. For instance, an IC foundry with at least a decade of unprofitability is deeply backwards in technology which could not be changed or improved by the existing management and production executives and working team (call collectively the managing team). The boldest and probably the only way is to retain an capable and seasoned managing team by ultrasuperior package with total trust and authorisation to reshape the foundry completely into a completely new one; otherwise there will mostly repeat another decade of what had been before. The same strategic implication applies to any aspect, especially with almost totally no competitiveness, when strategic critical bold undertaking is desperately necessary.

For the long run, a firm has to set an objective of an formidable market share by elevating in fundamental virtues, like brand approval by the consumer, brand popularity and loyalty, product differentiation, technology, know how, business networks, innovation, etc., and also through investment or divestment, M\&A, and other corporate deals. It is not necessarily to be huge or being huge that a firm is able to engage such formidable undertakings. A small firm could also find or create a market or market segment in which it commands monopoly market power with the lion market share! 


\section{Acknowledgment}

The authors owe deeply appreciations to Mr. Brett Chang for his full and prompt helps in doing the substantial part of the statistical and regression works which is far huger than one could image, and to Profs. Emmanuel Monod, Pierre Romelaer, Denis Darpy and Hervé Alexandre of U. ParisDauphine for their insightful discussions and academic inspiration, and to Prof. Cheng-Cherng Chen of National Taiwan U., Dean Charng Kao of National Dong Hwa U., Prof. Zhi-Hsin Yu of National Chi Nan U., Dean Shih-Shue Sher of Feng Chia U., and Prof. Hsiao-Ping Chu of Ling Tung U. for their valuable opinions and helps without reservation, and to Ph.D. candidate Huei-Ping Chen of National Taiwan U., Ms Jamie Lai and Mr. Donald Yeh for their persistent assistances. Of course, all errors and incompleteness remain the authors'.

\section{References}

[1] R. M. Almanza and C. M. Tomas, "Challenges and perspectives in using PIMS methodology to explain the success of the marketing strategy in businesses," Contaduría y administración, no. 234, pp. 79-99, JulyAugust 2011

[2] J. S. Bain, "The Profit Rate as a Measure of Monopoly Power," Quarterly Journal of Economics, vol 55 (2), pp. 271-293, February 1941

[3] J. S. Bain, "Relation of Profit Rate to Industry Concentration: American Manufacturing, 1936-1940," Quarterly Journal of Economics, vol 65 (3), pp. 293-324, August 1951

[4] M. Blaug, Economic Theory in Retrospect, rev ed., Homewood: Richard D. Irwin, 1968

[5] F. M. Bass, P. Cattin, and D. R. Wittink, "Firm Effects and Industry Effects in the Analysis of Market Structure and Profitability," Journal of Marking, vol. 15, pp. 3-10, February, 1978

[6] R. D. Buzzell, "The PIMS program of strategy research A retrospective appraisal," Journal of Business Research, vol. 57, pp. 478-483, 2004

[7] E. H. Chamberlin, The Theory of Monopolistic Competition, Cambridge: Harvard University Press, 1933

[8] H. P. Chu, "Is enlarging the market share the best strategy for maximizing profits?" African Journal of Business Management, vol. 5 (20), pp. $7992-$ 7999, 16 September, 2011

[9] R. Jacobson, "Unobservable effects and business performance," Marking
Science, vol. 9(1), pp. 74-85, Winter 1980

[10] R. Jacobson and D. Aaker, "Is Market Share all that it's Cracked up to be?" Journal of Marking, vol. 49, pp. 11-22, Fall 1985

[11] R. Jacobson and D. Aaker, "The Strategic Role of Product Quality" Journal of Marking, vol. 51, pp. 31-44, Fall 1987

[12] R. Jacobson, "Distinguishing among competing theories of the market share effect," Journal of Marking, vol. 52, pp. 68-80, October 1988

[13] M. LaPedus, "UMC Seeks to Shed Image as "Fast Follower,," Semiconductor Manufacturing \& Design web (http://semimd.com), 10 February 2012

[14] E. S. Mason, "Price and Production Policies of Large-Scale Enterprises," American Econ Rev, vol 29 (1 Supp), pp. 61-74 Mar 1939

[15] J. M. Perloff, Microeconomics, $6^{\text {th }}$ (global) ed., Essex, UK: Pearson Education Ltd. 2012

[16] S. A. Raza, M. S. Farooq, and N. Khan, "Firm and industry effects on firm profitability: an empirical analysis of KSE," MPRA Paper no. 36797, 21 February 2012

[17] J. Robinson, The Economics of Imperfect Competition, London : Macmillan, 1933

[18] R. P. Rumelt and R. Wensley, "In search of market share effect," Proceedings of the Academy of Management, pp. 2-6. 1981

[19] S. Schoeffler, R. D. Buzzell, and D. F. Heany, "Impact of strategic planning on profit performance," Harvard Business Review, pp. 137-145, March-April 1974.

[20] H. Simon, F. F. Bilstein, and F. Luby, Manage For Profit, Not For Market Share: A Guide to Greater Profits In Highly Contested Markets, Harvard Business Review Press, 1 April 2006

[21] L. R. Smeltzer, and S. P. Siferd, "Proactive Supply Management: The Management of Risk," International Journal of Purchasing and Materials Management, pp. 38-45, Winter 1998.

[22] A. Smith, An Inquiry into the Nature and Causes of the Wealth of Nations, (Electronic Classics Series, Pennsylvania State U. 2005), 1776

[23] N. Venkatraman, J. E. Prescott, "The market share-profitability relationship: testing temporal stability across business cycles," Journal of Management, vol. 16 no. 4, pp.783-805, December 1990

[24] C. Y. Woo, "Market share leadership: does it always pay off?" Proceedings of the Academy of Management, pp. 7-11, 1981

[25] C. Y. Woo, and A. C. Cooper, "Strategies of effective low share businesses," Strategic Management Journal, 2 pp. 301-318, 1981

[26] C. Y. Woo, and A. C. Cooper, "The surprising case for low market share," Harvard Business Review, 56(6), pp. 106-113, 1982

[27] C. P. Zeithaml, C. R. Anderson, and F. T. Paine "An Empirical Reexamination of Selected PIMS Findings," Proceedings of the Academy of Management, pp. 12-16, 1981 